\title{
Parametric study of fracture treatment parameters for ultra-tight gas reservoirs
}

\author{
Kelvin Abaa · John Yilin Wang • \\ Mku Thaddeus Ityokumbul
}

Received: 7 September 2011/Accepted: 5 May 2013/Published online: 26 June 2013

(C) The Author(s) 2013. This article is published with open access at Springerlink.com

\begin{abstract}
Tight gas reservoirs are expected to contribute significantly to the gas and energy supply all over the world. However, the productivity of tight gas wells, especially in the ultra-tight formations, is often lower than expected. One of the needed improvements in reservoir stimulation technology is in the advancement of fracturing fluids and techniques that can help create long and highly conductive fractures and reduce phase trapping at the face of the fracture. Introduction of aqueous-based fluids in ultralow permeability sands during hydraulic fracturing decreases the effective gas permeability and ultimate gas recovery. Unfortunately most fracture fluids currently deployed are aqueous based owing to their ease of preparation and low cost. This article aims to investigate the effect of different fracture fluid systems and fracture treatment parameters and then determine the one that achieves a balance of minimal fluid retention, optimal fracture geometry and low cost for ultra-tight gas reservoirs. In this article, a dataset of reservoir properties, petrophysical properties, and fracture treatment parameters has been developed based on a complete review of published geological and engineering data of ultra-tight gas reservoir. Then based on numerical parametric studies, the
\end{abstract}

This paper was originally presented as SPE 152877 at the 2012 Americas Unconventional Resources Conference held in Pittsburgh, Pennsylvania, USA, 5-7 June.

K. Abaa $(\bowtie) \cdot$ J. Y. Wang $\cdot$ M. T. Ityokumbul

Department of Energy and Mineral Engineering, Petroleum and Natural Gas Engineering, EMS Energy Institute, Pennsylvania State University, 202 Hosler Building, University Park, PA 16802, USA

e-mail: kelvinabaa@gmail.com

J. Y. Wang

e-mail: john.wang@psu.edu effect of pertinent design factors on hydraulic fracture propagation and geometry is quantified with a fracture simulator. The factors investigated include volumetric injection rate, gel loading and proppant size. Parametric variations of seven different injection rates, seven different fracture fluids, and three different proppants were studied. A final fracture treatment that achieves maximum fracture length, fracture width and proppant conductivity is determined to be optimal. Results of simulations show that optimal fracture geometry and fracture conductivity based on pumping limitations are obtained at an injection rate of 100 barrels per minute, a gel loading of 50 pounds per thousand gallons of linear gel and a proppant size of 20/40 mesh sand. This article brings new understanding of fracture behavior in ultra-tight gas reservoirs and serves as a guide for improved hydraulic fracturing practices in ultratight gas basins throughout the USA. The new knowledge obtained will help engineers design better fracture treatments and production strategies in the future.

Keywords Fluid retention - Ultra-tight gas sandstone . Gel loading · Fracture geometry · Proppant size · Fracture conductivity

$\begin{array}{ll}\text { List of symbols } \\ \mathrm{Cf} & \text { Product of fracture conductivity (md-ft) } \\ \mathrm{Cg} & \text { Rock compressibility }\left(\mathrm{psi}^{-1}\right) \\ E & \text { Young's modulus }(\mathrm{psi}) \\ \mathrm{FCD} & \text { Dimensionless fracture conductivity } \\ h & \text { Fracture height }(\mathrm{ft}) \\ k & \text { Average formation permeability (mD) } \\ \mathrm{Klc} & \text { Fracture toughness (psi- } \sqrt{ } \text { in) } \\ L & \text { Length of one wing of fracture (ft) } \\ \mathrm{pptg} & \text { Pounds per thousand gallon }\end{array}$

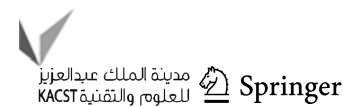


$\mathrm{Pi} \quad$ Initial reservoir pressure (psi)

$\mathrm{Sw} \quad$ Water saturation fraction (fraction)

Swi Initial (not irreducible) water (fraction)

$T \quad$ Temperature $\left({ }^{\circ} \mathrm{F}\right)$

$w \quad$ Width of propped fracture (ft)

$\phi \quad$ Porosity (fraction)

v Poisson's ratio (fraction)

$\mu \quad$ Fluid viscosity (cp)

$\sigma \mathrm{Hmin}$ Closure stress gradient (psi/ft)

\section{Introduction}

Natural gas from tight gas sands is expected to contribute significantly to US gas reserves as the demand for energy increases and improvements in drilling and completion technologies continues. Tight gas reservoirs refer to gasbearing sandstones or carbonates with in situ permeabilities of $<0.1$ millidarcy $(\mathrm{mD})$. Ultra-tight gas reservoirs are a subclass of tight gas reservoirs that have an average permeability as low as or $<0.001 \mathrm{mD}$. They may or may not contain natural fractures. They are characterized by "abnormally pressured, gas-saturated accumulations in low-permeability rocks" and they have no down-dip water leg. Hydraulic fracturing is one of the key completion technologies that has been used to successfully produce gas from these reservoirs in commercial amounts; however, like all unconventional reservoirs, there is still a lot that is not known about them.

One of the major challenges involved in stimulation of ultra-tight gas sandstones is fluid retention. Fluid retention/ phase trapping is one of the major formation damage mechanisms that impedes the production of natural gas on flowback of a fractured well and overall gas recovery. Other damage mechanisms in low permeability reservoirs include gel residue, proppant crushing, and migration of fines. In this article, emphasis is placed on fluid retention since literature review has identified fluid retention as the most prevalent cause of reduced gas productivity from tight gas reservoirs. In some cases, phase trapping/fluid retention has accounted for a loss of about $20 \%$ reduction of poststimulation gas recovery.

This article presents a methodology used to design a fracture fluid treatment that achieves a balance of optimal fracture geometry, fracture conductivity and low cost. The methodology used involves the following steps: (1) Carry out a detailed literature review of the major stimulation challenge facing ultra-tight gas sandstones as well as the fracture fluids currently employed in the industry. (2) Model and simulate hydraulic fracture propagation and design fracture treatment for a case study ultra-tight sand formation. (3) Run parametric study and quantify the effect of fracturing fluid injection rate, polymer concentration, and proppant size on fracture geometry. (4) Analyze the simulated results from parametric study and recommend fracture treatment design criteria.

\section{Fracture fluids and its impact}

Fluid retention and phase trapping damage

Most ultra-tight gas sands fall into the classification of subnormally saturated or desiccated reservoirs, this means that there is a huge amount of capillary pressure energy which needs to hold or imbibe a fluid in the porous media (Bennion et al. 2000). Phase trapping/fluid retention effects can occur in gas reservoirs in both water- and hydrocarbonbased fluids. In most of these formations, water is the wetting phase, which tends to eliminate the affinity for spontaneous imbibitions of a hydrocarbon-based liquid phase into the matrix surrounding the wellbore. Figure 1 (Bennion et al. 2000) shows the relationship between water of saturation and capillary pressures for reservoirs of varying permeabilities. The capillary pressure decreases as the water of saturation increases but more importantly the capillary pressure increases with decreasing permeability. This figure illustrates the effect that increased water saturation has on very low permeability reservoirs. If a waterbased fluid is introduced into the formation, a high water of saturation in the flushed zone is generated and this could severely impede the flow of gas during flowback and production (Cramer 1995; Wang et al. 2010). This process is more pronounced in the fracture face and reduces the conductivity of the propped pack. Figure 2 (Bennion et al. 2000) shows that the relative permeability of gas decreases with increasing water saturation. This illustrates the effect

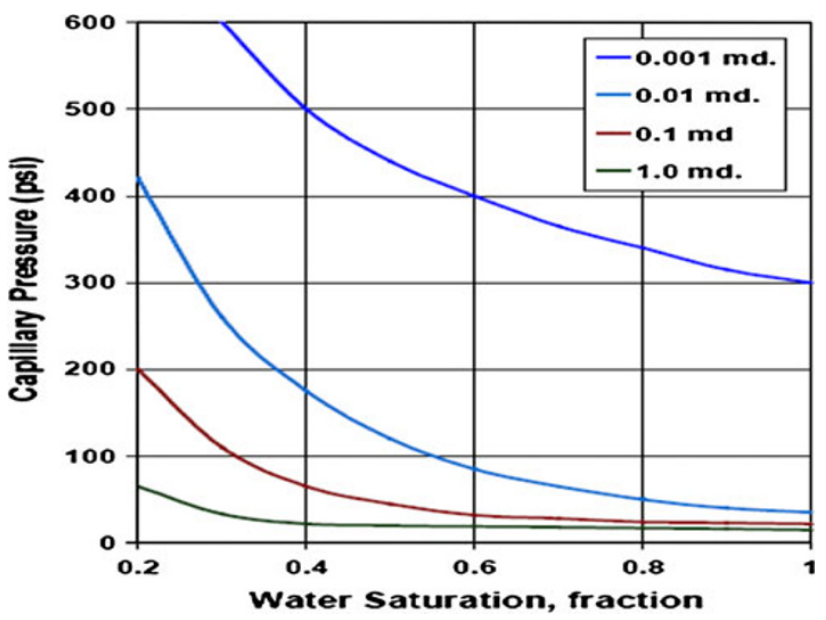

Fig. 1 Effect of water of saturation on capillary pressure in low permeability sandstones (Bennoin et al. 2001) 


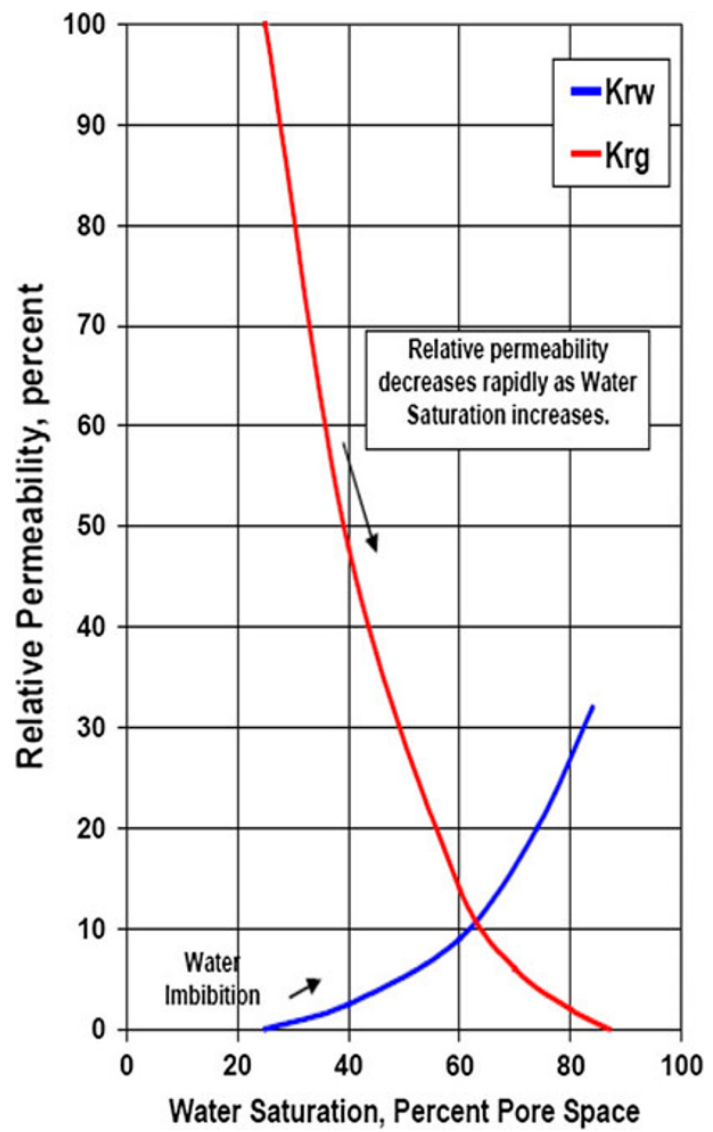

Fig. 2 The effect of imbibition of water on gas relative permeability in low permeability sandstones (Bennion et al. 2000)

of fluid retention on non-wetting phase (gas) via the introduction of water- or aqueous-based fracture fluids while fracturing. The overall effect is a restriction of gas flow during flowback and reduced ultimate recovery of hydrocarbons in ultra-tight gas sands. Other issues that affect the successful stimulation of ultra-tight gas formations include the damage on fracture conductivity packs when breakers are used to breakdown chemicals used in fracturing of ultra-tight gas sands (Warpinski 1991).

\section{Available fracture fluids}

Fracturing fluid is one of the key components of the hydraulic fracturing process and it can determine the response of the well to stimulation. Some of the major features that fracture fluids must possess include:

1. Enough viscosity to create adequate fracture width and to effectively transport and distribute proppant in the fracture.

2. Good fluid loss control to obtain the required fracture extension and width with minimum fluid volumes.

3. Have compatibility with the formation to minimize formation damage.
4. Fluid viscosity must breakdown after proppant is placed to permit maximum fracture conductivity.

5. Cost effectiveness.

There are a variety of fracturing fluids that can achieve the aforementioned properties. Fracturing fluids can be classified into conventional and unconventional fracturing fluids (Gupta 2009).

Conventional fracturing fluids include water-based and polymer-containing fluids (both linear and cross-linked gels); hydrocarbon-based fluids and energized fluids and foams. Unconventional fracturing fluids include viscoelastic surfactants fluids, viscoelastic surfactant foams, liquid $\mathrm{CO}_{2}$-based fluids, aqueous methanol-based fluids and gelled liquefied petroleum-based fluids. The use of these fluids is based on the lithologies of the different formations to be fractured and the compatibility of the fracturing fluid with the formation. For tight gas sands the major damage mechanism is fluid retention; the use of aqueous-based fluids causes fluid retention or phase trapping, poor proppant placement and proppant pack gel damage which can lead to severe impairment of gas productivity. Unconventional fracturing fluids on the other hand are expensive, tedious to prepare and in the case of liquefied petroleum gas are limited by safety issues and chance of fire hazards. This article aims to design a fracture fluid treatment that minimizes fluid retention, achieves optimal fracture geometry and fracture conductivity at a low cost.

Fracture design and fracture property simulation

The design methodology used in this project assumes that the design calculations represent actual, quantitative fracture behavior. High speed computers can be used to solve the equations governing fracture growth and proppant transport calculations. A commercial fracture simulator was used to simulate fluid design and fracture properties for this project. In this mode, one can generate a treatment schedule based on the reservoir parameters. The fluids and proppants suitable for the formation are selected and used to generate a treatment design. The user can then specify a dimensionless conductivity criterion and a pump schedule that achieves this target which will be modeled. Fracture geometries and properties for the fracture treatment design are generated as simulator output.

Fracture model used for simulation

The behavior of hydraulic fracture growth can vary depending on the formation being stimulated. For example, in formations there is a large difference in the magnitude of horizontal principal stresses, and the growth of long thin fractures in one direction is expected. FracproPT allows 
users to import a type of fracture growth behavior that may be unique to a certain formation.

In tight gas sandstones, extensive micro-seismic fracture mappings have shown that there is more fracture height confinement than is expected from conventional confining mechanisms such as stress barriers and permeability facies (Wright et al. 1999). This phenomenon is referred to as composite layering effect and was first adopted by Warpinski (1991) (Wright et al. 1999). This explains why it is easier for fractures to grow along layers, i.e., fracture length across layer interfaces (fracture height). Figure 3 shows a diagrammatic representation of the composite layering effect.

In FracproPT, the 3D shear-decoupled model is used to simulate this fracture growth behavior. The 3D sheardecoupled model predicts longer and more confined hydraulic fractures caused by the introduction of a composite layering effect. This model is used to simulate fracture growth behavior for this research because layered tight gas sands have been shown to exhibit this behavior.

\section{Reservoir description}

The formation used for this study consists of a shale-sandshale sequence. The pay zone used in this formation is almond sandstone with a reservoir permeability of $0.001 \mathrm{mD}$ and subsurface depth of 10,000 ft. The reservoir parameters for the ultra-tight permeability sandstone used in this study are presented in Table 1 . The geophysical parameters for the reservoir case study are presented in Table 2 .

FracproPT allows input of reservoir and petrophysical properties in the reservoir parameters page of the fracture design mode of the software. It provides a reservoir table where the layers that make up the reservoir can be defined by entering the depth to the top of each layer. All the reservoir and geophysical properties for each layer are also defined here. Figure 4 shows a graphical representation of the three-layer model showing the important geophysical properties used in this study. FracproPT was used to

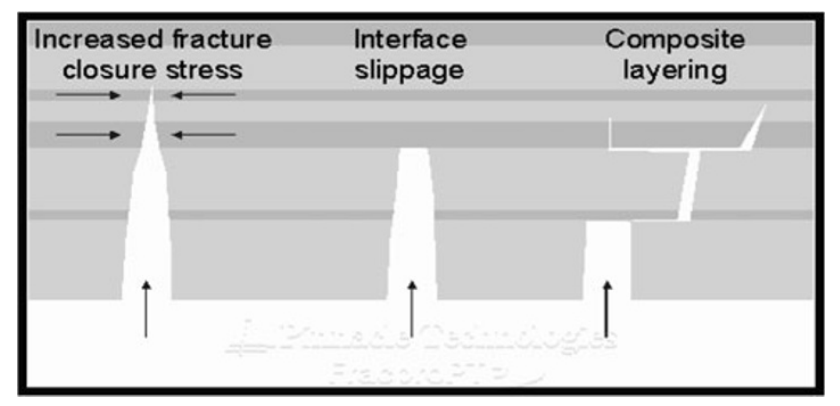

Fig. 3 Diagrammatic representation of the composite layering effect (Pinnacle Technologies 2007)
Table 1 Reservoir data used for fracture design

\begin{tabular}{ll}
\hline Reservoir parameters & \\
\hline Initial reservoir pressure $(\mathrm{psi})$ & 5,811 \\
Static reservoir temperature $\left({ }^{\circ} \mathrm{F}\right)$ & 200 \\
Porosity $(\%)$ & 0.65 \\
Net sand thickness (ft) & 40 \\
Layer formation depth (ft) & 10,000 \\
Permeability (mD) & 0.001 \\
Gas viscosity (cp) & 0.01 \\
Water saturation $(\%)$ & 0.4 \\
Gas gravity, dimensionless & 0.7 \\
Compressibility (psi ${ }^{-1)}$ & 0.000172 \\
\hline
\end{tabular}

Table 2 Geophysical properties used for fracture design

\begin{tabular}{ll}
\hline Geophysical parameters & \\
\hline Poisson's ratio, dimensionless & 0.20 \\
Young's modulus (psi) & $5,000,000$ \\
Toughness (psi- $\sqrt{ }$ in.) & 1,000 \\
Closure gradient $(\mathrm{psi} / \mathrm{ft})$ & 0.8606 \\
Average fracture gradient $(\mathrm{psi} / \mathrm{ft})$ & 0.9105 \\
\hline
\end{tabular}

calculate the stress based on closure stress gradient of sandstone layer of the reservoir.

Fracture fluid selection

The major technical factors that influence the choice of fracturing fluid in any design include viscosity fluid loss, fluid friction loss, gel damage, and compatibility with reservoirs. Others such as cost and availability are economical factors that also receive attention once the fluid meets the technical requirements for a particular stimulation job (Gidley et al. 1989).

In this article, emphasis will be placed on fluid viscosity and compatibility with rock formation. These two factors are the most important in selection of a fluid before other factors are considered. They are also the controllable parameters that determine the initial selection of fracture fluids that meet design criteria in this reservoir case study.

\section{Viscosity}

The viscosity of a fracture fluid affects the width and length profile of the created fracture as well as the proppant distribution in the fracture. In most designs, moderate or high viscosity fluids are used because of their ability to create sufficient fracture width and proppant carrying capacity. The use of low viscosity fluids such as slickwater is the predominant trend because of their low cost and availability. 


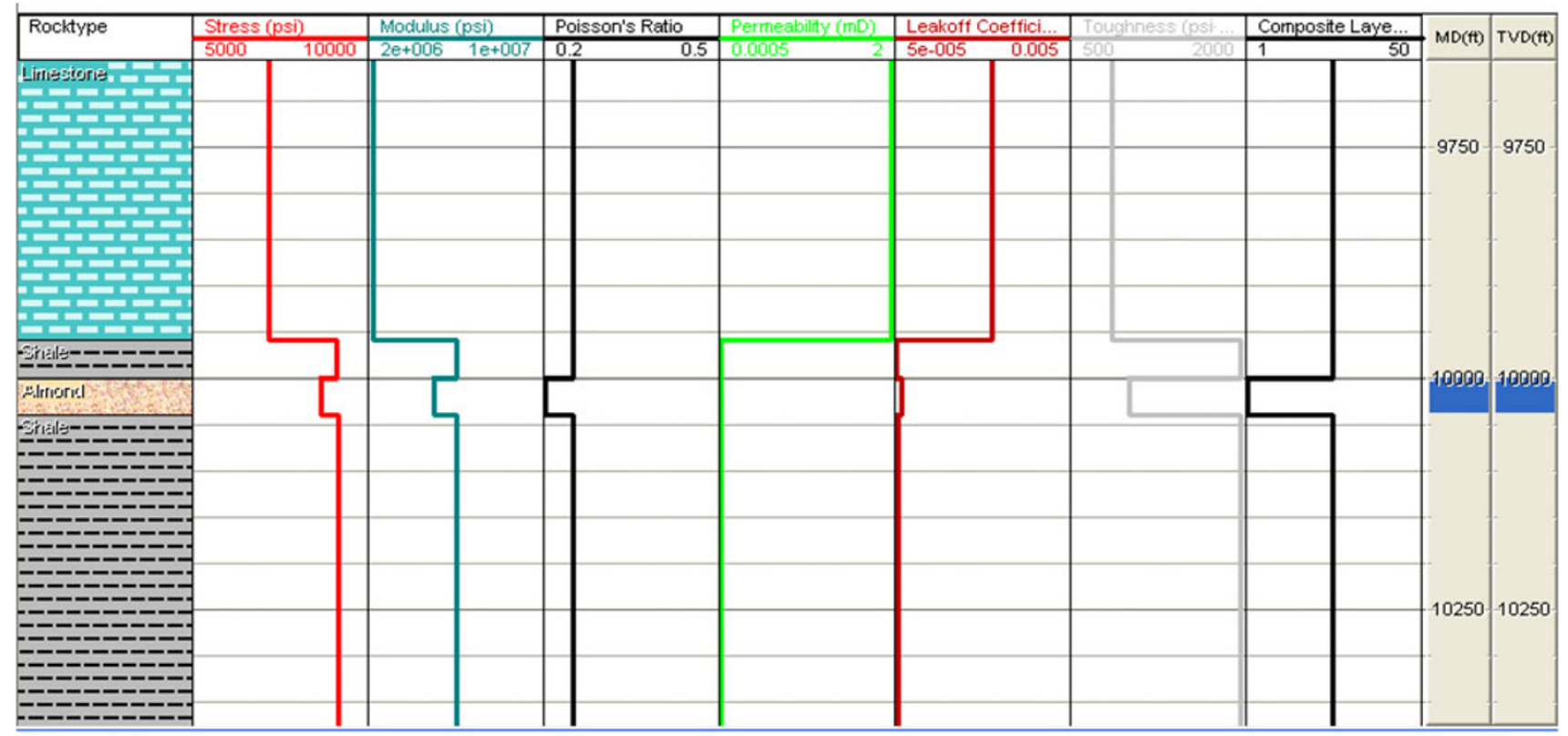

Fig. 4 Graphical representation of geophysical properties of formation

At fracture flow conditions, proppants will be fully suspended if the fluid viscosity along the fracture is at least $50-100 \mathrm{cp}$ during pumping (Gidley et al. 1989). On exposure to the reservoir after pumping, the fluid can lose its viscosity allowing the proppant to settle before closure of the fracture, resulting in a partially propped fracture and loss in effective fracture conductivity.

Gidley et al. (1989) presented a fluid selection process based on viscosity (Gidley et al. 1989). It involves the following steps:

1. Select a fluid that meets the viscosity requirement for full proppant suspension after a specified time of exposure to the reservoir before closure of the fracture.

2. Reduce the viscosity of the fluid by decreasing the gel loading to achieve less than complete suspension yet placing the treatment successfully.

3. Test lower viscosity fluids to form equilibrium banks if wider fractures are needed.

Final fluid selection is made once all other influencing factors are considered.

\section{Reservoir compatibility}

Many reservoir rocks are sensitive to fluids and additives present in fracture fluids. Therefore, the sensitivity of the formation and formation fluids must be considered before the selection of a fracture fluid.

Clay containing formations are easily hydrated by water and swell. The use of aqueous-based fluids can cause swelling of clay. The swelling of claying can lead to an unstable wellbore, stuck pipe and damage of the fracture by migration of fines. Fracture fluids should be selected to minimize the swelling of clay. The use of $2 \% \mathrm{KCl}$ in water-based fluids and other chemicals can prevent clay swelling.

Another factor is the precipitation of minerals, especially of iron in contact with fracture fluids. Chemical additives should be used when this is known. Oil-based fluids should be used if formation is sensitive to water composition. In this study, there is a potential for clay swelling as the layers lie adjacent to the pay zone, i.e., shale barriers contain clay. Therefore, clay swelling was a factor considered in this treatment design.

The viscosity criterion used for selection of fluid for this study was to obtain $200 \mathrm{cp}$ apparent viscosity at $40 \mathrm{~s}^{-1}$ after $1 \mathrm{~h}$ of exposure to the reservoir temperature. The viscosity parameters for fluid selection are:

1. A minimum apparent viscosity of $50 \mathrm{cp}$.

2. A shear rate of $100 \mathrm{~s}^{-1}$ in the fracture.

3. An exposure time of $1 \mathrm{~h}$ of fracturing fluid in fracture at $200{ }^{\circ} \mathrm{F}$.

These values were input into Fracpro's fluid selection page to generate a list of potential fracture fluids. The study objective was to consider all possible fluids including low viscosity fluids such as slickwater and linear gelled fluids as long as they achieve proppant placement at low costs. At this point, the other factors such as cost, gel damage, and fluid loss were used to narrow down the choice of fluids. This is desirable so as to avoid excessive design calculations. Emulsions and foams were eliminated because of

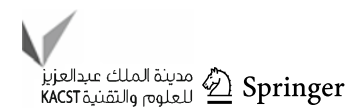


their high treating pressures and high cost. The final group of selected fluids consists of slickwater and linear gel fluids of hydropropylguar (HPG) ranging from 10 to 60 pounds per thousand gallon (pptg) of gel. The final group of fluids selected for this design is presented in Table 3.

\section{Injection rates}

The effect of injection rate on fracture propagation in ultratight gas sandstones was modeled using different injection rates as simulator input. Table 4 shows different injection rates used in this study as simulator input.

\section{Proppant selection}

The two major factors used to select proppant for this design are the proppant conductivity under stress and the damage factor as a result of gel residue. The effective permeability of proppant varies with stress. The higher the stress on the proppant, the lower is its effective permeability. Proppants are selected based on its permeability at the stress in the pay zone. Proppant permeability is also dependent on polymer concentration and non-Darcy effects. Fracpro models this permeability reduction by assigning factor that accounts for damage to each proppant from both polymer concentration and non-Darcy effects. Gel damage of typical gelled fluids can result to a total damage factor of about $20 \%$.

Assuming a damage factor of about $20 \%$ and specifying the stress in the pay zone calculated as 8,624 psi, Fracpro

Table 3 Selected fluid systems and gel composition

\begin{tabular}{llc}
\hline Fluid system & $\begin{array}{l}\text { Gel loading } \\
\text { (pptg) }\end{array}$ & $\begin{array}{l}\text { Apparent } \\
\text { viscosity at } \\
200^{\circ} \mathrm{F}(\mathrm{cp})\end{array}$ \\
\hline $5 \%$ Slickwater & 5 & 3.22 \\
10 pptg Linear gel HPG & 10 & 4.63 \\
20 pptg Linear gel HPG & 20 & 6.31 \\
30 pptg Linear gel HPG & 30 & 9.82 \\
40 pptg Linear gel HPG & 40 & 24.23 \\
50 pptg Linear gel HPG & 50 & 42.37 \\
60 pptg Linear gel HPG & 60 & 66.85 \\
\hline
\end{tabular}

Table 4 Injection rates used for parametric study outputs a list of proppants that achieve the highest conductivity under these conditions. The final proppant selection is presented in Table 5 .

\section{Results and discussion}

Based on the reservoir properties, petrophysical properties and fracture treatment parameters mentioned earlier, different fracture treatment parameters were investigated and their effects on fracture propagation and geometries were quantified. These factors include seven different injection rates, seven different fracture fluids based on gel loading, and three different proppant sizes.

Effect of volumetric injection rate

Simulations were run using the different fracturing fluids and injection rates. The various combinations were analyzed and compared. The injection rates of 10, 20, 40, 50, 60,80 , and 100 barrels per minute (bpm) were run and the corresponding propped fracture lengths were calculated for each injection rate. Results of simulated fracture length for each injection rate and gel loading are presented in Table 1. Figure 5 shows the plot of various injection rates and simulated propped fracture lengths. For slickwater, the

Table 5 Selected proppants used in study

\begin{tabular}{llll}
\hline $\begin{array}{l}\text { Proppant } \\
\text { type }\end{array}$ & $\begin{array}{l}\text { Proppant } \\
\text { size }\end{array}$ & $\begin{array}{l}\text { Proppant permeability } \\
\text { at } 8,624 \mathrm{psi} \\
\text { closure }(\mathrm{mD})\end{array}$ & $\begin{array}{l}\text { Total } \\
\text { damage } \\
\text { factor }\end{array}$ \\
\hline Arizona sand & $12 / 20$ & 73,000 & 0.27 \\
Arizona sand & $20 / 40$ & 78,000 & 0.22 \\
Arizona sand & $40 / 70$ & 43,500 & 0.29 \\
\hline
\end{tabular}

Plot of Volumetric Injection Rate vs. Fracture Length

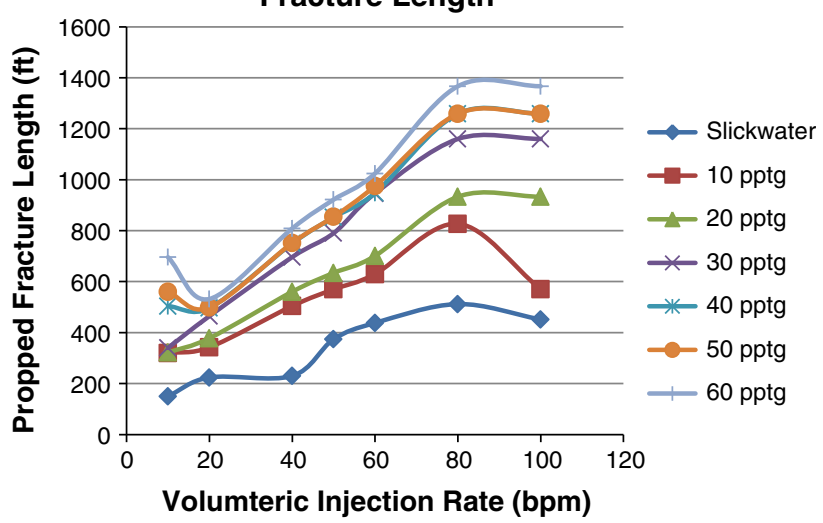

Fig. 5 Plot of volumetric injection rate vs. propped fracture length 


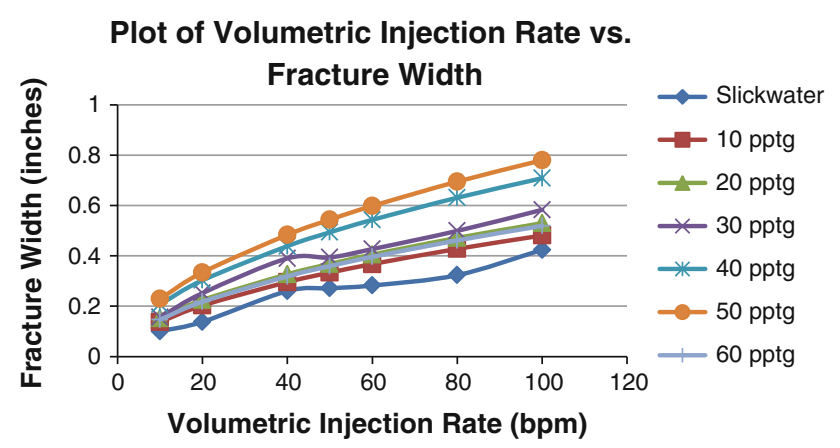

Fig. 6 Plot of volumetric injection rate vs. pumped fracture width

propped length of the fracture increased with injection rate. The same conclusions were drawn for linear gelled fluids. As the injection rate increased, the viscous forces override the forces of gravity and the proppant placement efficiency increases. The volumetric injection rate also influences the created fracture width. Figure 6 shows the plot of simulated fracture widths at various injection rates. It shows that the fracture width increases with injection rate. Maximum fracture width results from an injection flowrate of $100 \mathrm{bpm}$. It was concluded that gelled fluids yield wider fractures than slickwater. Tabulated results of fracture width for injection rate and gel loading are presented in Table 7.
Effect of polymer concentration/gel loading

The propped fracture lengths and fracture widths were simulated for slickwater and various concentrations of linear gel. Tables 6 and 7 list the calculated fracture lengths and widths for the different fracture fluids. Figure 7 shows the simulated propped lengths for different concentrations of linear gel and slickwater which are assumed to have no gel present, i.e., $<5$ pounds per thousand gallons of gel. The propped length increases with gel loading. Gel loading is proportional to fluid viscosity, therefore, more gel loading results in increased apparent fluid viscosity. It is observed that in low viscosity fluids, i.e., fluids with $<20$ pptg, the propped length is shorter. In low viscosity, fracturing fluids the settling rate of proppant is relatively high. This is because the fluid does not have enough gel strength to carry proppants far into the fracture and gives shorter propped fractures. At gel loadings $>30 \mathrm{pptg}$, a dramatic increase in propped fracture length is observed. High viscosity fluids allow little proppant settling and can carry proppant farther into the fracture. Propped fracture length for different proppant sizes are presented in Table 8 . The created fracture widths were also simulated for the same concentrations of linear gel. Figure 8 shows simulated fracture widths for slickwater $(0 \mathrm{pptg})$ at various concentrations of linear gel. It shows that fracture width is

Table 6 Simulated propped fracture length ( $\mathrm{ft}$ ) for injection rates and gel loading

\begin{tabular}{|c|c|c|c|c|c|c|c|}
\hline \multirow[t]{2}{*}{ Injection rate (bpm) } & \multicolumn{7}{|c|}{ Fracturing fluids with different loading of gels in pounds per thousand gallons } \\
\hline & Slickwater & $10 \mathrm{pptg}$ & 20 pptg & 30 pptg & 40 pptg & 50 pptg & $60 \mathrm{pptg}$ \\
\hline 10 & 150 & 320 & 322 & 340 & 504 & 560 & 696 \\
\hline 20 & 224 & 342.37 & 378 & 464.7 & 496.26 & 498.68 & 532 \\
\hline 40 & 230 & 504.52 & 560.58 & 696.54 & 749.97 & 751.9 & 809 \\
\hline 50 & 373.9 & 570.12 & 634.36 & 790.43 & 852.94 & 854.64 & 922 \\
\hline 60 & 437.9 & 629.7 & 701.069 & 946.27 & 947.65 & 975.44 & 1024.7 \\
\hline 80 & 512 & 827.1 & 933.26 & 1160.1 & 1258.9 & 1259.2 & 1367 \\
\hline 100 & 451.5 & 570.12 & 933.26 & 1160.1 & 1258.9 & 1259.2 & 1367 \\
\hline
\end{tabular}

Table 7 Simulated pumped fracture width (in.) for injection rate and gel loading

\begin{tabular}{|c|c|c|c|c|c|c|c|}
\hline \multirow[t]{2}{*}{ Injection rate (bpm) } & \multicolumn{7}{|c|}{ Fracturing fluids with different loading of gels in pounds per thousand gallons } \\
\hline & Slickwater & 10 pptg & 20 pptg & $30 \mathrm{pptg}$ & $40 \mathrm{pptg}$ & $50 \mathrm{pptg}$ & $60 \mathrm{pptg}$ \\
\hline 10 & 0.1002 & 0.1373 & 0.1526 & 0.1558 & 0.2071 & 0.2289 & 0.1465 \\
\hline 20 & 0.1379 & 0.2027 & 0.2244 & 0.2518 & 0.3028 & 0.3342 & 0.2175 \\
\hline 40 & 0.2601 & 0.2957 & 0.3266 & 0.39 & 0.4386 & 0.4835 & 0.3184 \\
\hline 50 & 0.2711 & 0.3333 & 0.3678 & 0.3937 & 0.4934 & 0.5437 & 0.3591 \\
\hline 60 & 0.2822 & 0.3673 & 0.4051 & 0.42681 & 0.543 & 0.5981 & 0.3959 \\
\hline 80 & 0.3233 & 0.4277 & 0.4713 & 0.4991 & 0.6309 & 0.6948 & 0.4614 \\
\hline 100 & 0.4237 & 0.4809 & 0.5297 & 0.5829 & 0.7084 & 0.7799 & 0.5191 \\
\hline
\end{tabular}


Fig. 7 Plot of gel loading vs. propped fracture length

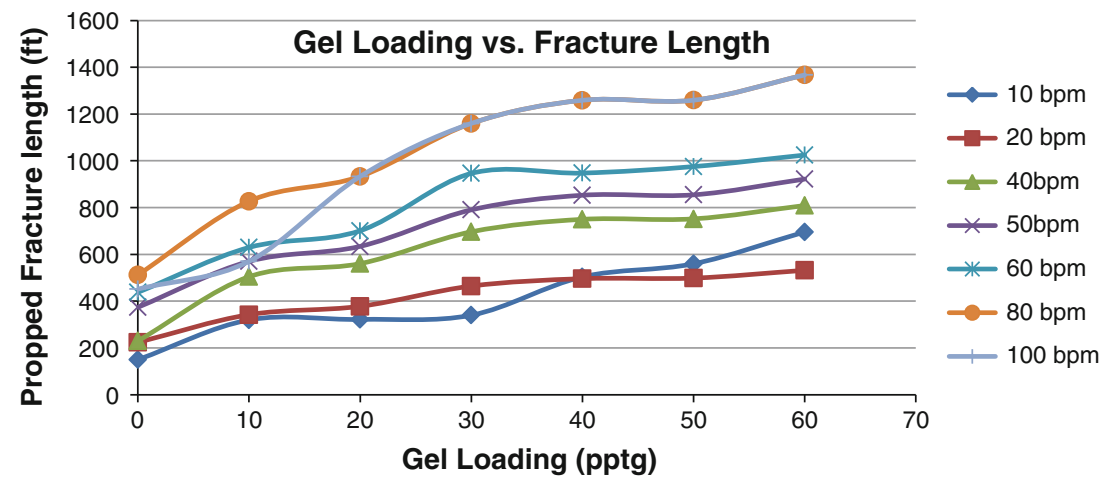

Table 8 Simulated propped fracture lengths (ft) for various proppant sizes at $50 \mathrm{bpm}$

\begin{tabular}{lllc}
\hline Gel loading (pptg) & \multicolumn{3}{l}{ Propped length in $\mathrm{ft}$ for various proppant size } \\
\cline { 2 - 4 } & $12 / 20$ mesh & $20 / 40$ mesh & $40 / 70$ mesh \\
\hline 0 & 345 & 373.9 & 392.9 \\
10 & 432.5 & 570.12 & 649.37 \\
20 & 495.9 & 634.36 & 713.61 \\
30 & 671.2 & 790.43 & 869.68 \\
40 & 750 & 852.94 & 932.19 \\
50 & 798.2 & 854.64 & 933.89 \\
60 & 810 & 922 & $1,001.25$ \\
\hline
\end{tabular}

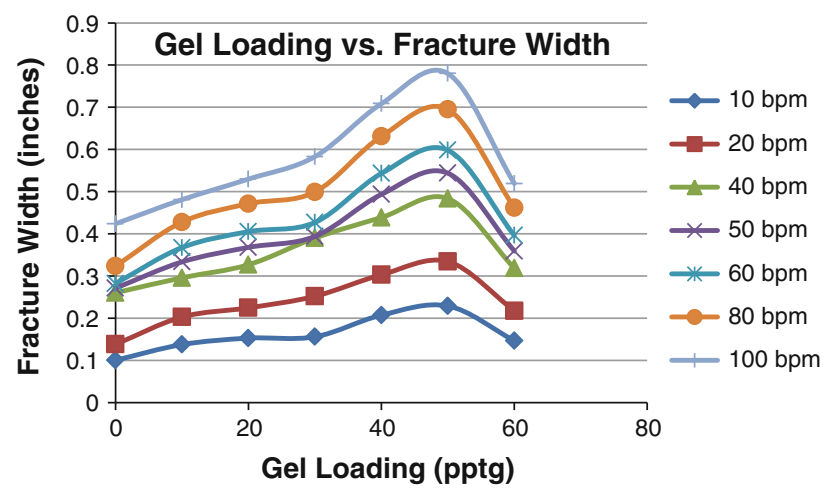

Fig. 8 Plot of gel loading vs. pumped fracture width

proportional to the gel loading of the fracturing fluid. Increasing the gel loading increases the fluid viscosity, which results in greater fracture widths. However, there is a sharp reduction in fracture width at a gel loading of $60 \mathrm{pptg}$ as shown in Fig. 8. This is attributed to the formation of a filter cake which reduces the effective width of the fracture.

\section{Effect of proppant size}

The effect of proppant size on fracture properties was also simulated in this study. The propped fracture half-length at different gel loadings were simulated for various proppant

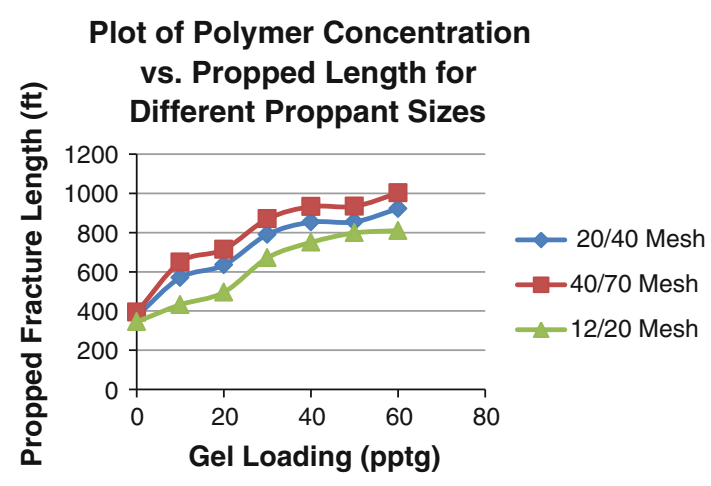

Fig. 9 Plot of gel loading vs. propped fracture length for various proppant sizes

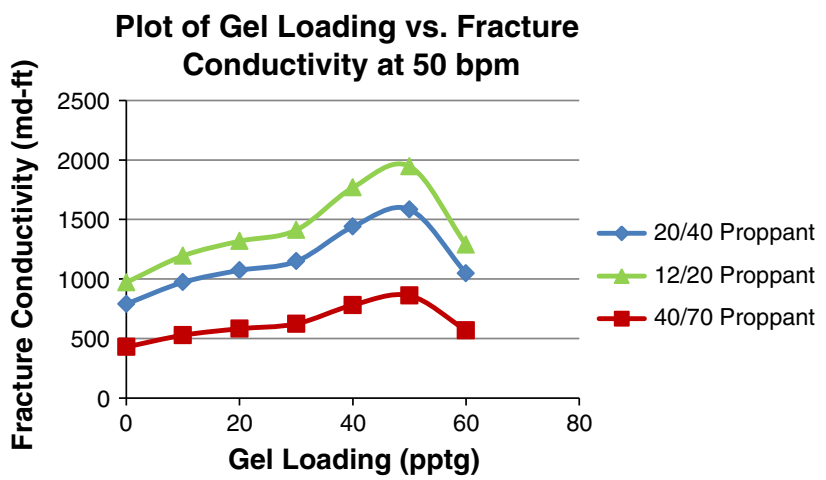

Fig. 10 Plot of gel loading vs. fracture conductivity for various proppant sizes

sizes. The proppant sizes used for this run include 12/20 mesh, 40/70 mesh and 20/40 mesh sizes. Table 3 and Table 4 show the simulated results of propped half-lengths and propped fracture conductivity for the three proppant sizes at $50 \mathrm{bpm}$. Figure 9 shows a plot of propped length vs. proppant size for different gel loadings. The 40/70 mesh proppant has a greater propped length than larger sized proppants of $12 / 20$ and 20/40 mesh. This shows that smaller sized proppants are easier to transport deeper into the fracture than larger sized proppants. No simulations were run for the effect of proppant size on pumped width 
and dimensionless fracture conductivity. Hydraulically created width is dependent on fluid rheology, not on proppant properties. Conversely, larger sized proppants have greater pack permeability than smaller sized proppants. Figure 10 shows the effect of proppant size on fracture conductivity for different gel loadings at $50 \mathrm{bpm}$. From this figure, we can see that the fracture conductivity increases with gel loading as the fluid viscosity also increases. This in turn influences the created fracture width and hence fractures conductivity. This trend was observed for all injection rates (Fig. 7). Optimal fracture conductivity is achieved at $12 / 20$ proppant mesh because of its large particle size relative to the $20 / 40$ and $40 / 70$ proppant.

\section{Conclusions}

A new fracture treatment for ultra-tight gas sandstones was developed. Parametric variations of the controllable treatment parameters such as fluid properties and proppant size were used to design an optimal fracture treatment. The following conclusions were gathered from this research and applied to stimulation of ultra-tight gas reservoirs.

1. The created fracture length increases with increasing volumetric injection rate.

2. Fracture width is proportional to volumetric injection rate. Increasing the injection rate serves to increase the net pressure, fracture volume and expands the fracture width.

3. The created fracture length is directly related to the gel loading. Increasing the gel loading increases the apparent viscosity of the fracturing fluid (which in turn reduces leakoff) and also increases the net pressure (which in turn increases the fracture length).

4. Hydraulic fracture width is directly related to the fluid viscosity gel loading. Lower gelled fracturing fluids exhibit smaller fracture widths than higher gelled fluids.

5. Increasing volumetric injection rate may serve to offset narrow fracture widths, since fracture widths are obtained by increasing the injection rate.

6. At lower gel loading $(20 \mathrm{pptg})$, increasing the injection rate does not significantly increase fracture length. At higher gel loadings (40 pptg), increasing the injection rate significantly increases the fracture width.

7. Optimum fracture width is obtained at a gel loading of 50 pptg. Further increase in gel loading results in loss in fracture width because of the formation of a filter cake on fracture walls.

8. Increasing the fluid viscosity increases proppant transport. Thus, longer propped fracture lengths are obtained at higher gel loadings.
9. Maximum propped fracture length is obtained at 60 pptg for any proppant size.

10. Decreasing proppant size improves proppant transport and increases the propped fracture length. A 40/70 mesh proppant has the largest propped fracture length, while a 12/20 mesh size proppant has the least propped fracture length.

11. On the other hand, reducing the proppant size results in lower propped fracture conductivity. Smaller sized proppants have less permeability than larger sized proppants.

12. Optimum fracture conductivity is obtained at $50 \mathrm{pptg}$, further increase in gel loading results in reduced fracture conductivity.

13. Parametric analysis of the results suggest that the design criteria for optimal stimulation of tight gas sands is:

- an injection rate of $100 \mathrm{bpm}$

- a gel loading of 50 pptg of linear HPG

- a proppant size of $20 / 40$ mesh sand

14. The optimal design parameters result in reduced fluid treatment volumes, hence a reduced aqueous phase in formation and minimize the effect of fluid retention. It also provides the optimal gel loading that achieves best effective width and minima gel damage.

Future work

The future work direction for this research project will be to input fracture properties obtained from the fracture simulator into a finite difference simulator to assess the post-fracture well performances of each treatment design. This is a more comprehensive approach to post-fracture evaluation, since finite difference simulators do not rely on pseudo-steady state assumptions. They also offer the prospect of modeling the effects of fracturing and reservoir heterogeneity. Different fracture properties and designs should be modeled to understand the well's response and help to prepare better recover strategies.

Open Access This article is distributed under the terms of the Creative Commons Attribution License which permits any use, distribution, and reproduction in any medium, provided the original author(s) and the source are credited.

\section{References}

Bennion DB, Thomas FB, Ma T (2000) Formation damage processes reducing productivity of low permeability gas reservoirs. Paper SPE 60325-MS presented at SPE rocky mountain regional/lowpermeability reservoirs symposium and exhibition, Denver, CO, 12-15 March 
Cramer DD (1995) The evolution of hydraulic fracturing in the almond formation. Paper SPE 30480-MS presented at SPE annual technical conference and exhibition, Dallas, TX, Oct $22-25$

Gidley JL, Holditch SA, Nierode DE,Veatch Jr RW (1989) Recent advances in hydraulic fracturing. Society of petroleum engineers monograph 12, Richardson

Gupta DVS (2009) Unconventional fracture fluids for tight gas reservoirs. Paper SPE 119424-MS presented at the SPE hydraulic fracturing technology conference, The Woodlands, TX, January 19-21

Pinnacle Technologies (2007). FracproPT, http://www.fracpro.com/ fracpropt.html
RP 56 (1983) Recommended practices for testing sand used in hydraulic fracturing operations first edition, API, Dallas

Wang JY, Holditch SA, McVay DA (2010) Modeling of fracture fluid cleanup in tight gas wells. Paper SPE 119624. SPE J 15(3):783-793

Warpinski NR (1991) Hydraulic fracturing in tight, fissured media. J Pet Tech 43(2):146-151, 208-209

Wright CA, Weijers L, Davis EJ, Mayerhofer M (1999) Understanding hydraulic fracture growth: tricky but not hopeless. Paper SPE 56724 presented at the SPE Annual Technical Conference and Exhibition, Houston, Texas, 3-6 Oct 1999 